\title{
Influence of air quality model resolution on uncertainty associated with health impacts
}

\author{
T. M. Thompson and N. E. Selin \\ Joint Program on the Science and Policy of Global Change, Massachusetts Institute of Technology, 77 Massachusetts, Ave., \\ Bldg E19-411, Cambridge, MA 02139, USA
}

Correspondence to: T. M. Thompson (tammyt@mit.edu)

Received: 28 March 2012 - Published in Atmos. Chem. Phys. Discuss.: 8 June 2012

Revised: 7 September 2012 - Accepted: 3 October 2012 - Published: 26 October 2012

\begin{abstract}
We use regional air quality modeling to evaluate the impact of model resolution on uncertainty associated with the human health benefits resulting from proposed air quality regulations. Using a regional photochemical model (CAMx), we ran a modeling episode with meteorological inputs simulating conditions as they occurred during August through September 2006 (a period representative of conditions leading to high ozone), and two emissions inventories (a 2006 base case and a 2018 proposed control scenario, both for Houston, Texas) at 36, 12, 4 and $2 \mathrm{~km}$ resolution. The base case model performance was evaluated for each resolution against daily maximum 8 -h averaged ozone measured at monitoring stations. Results from each resolution were more similar to each other than they were to measured values. Population-weighted ozone concentrations were calculated for each resolution and applied to concentration response functions (with $95 \%$ confidence intervals) to estimate the health impacts of modeled ozone reduction from the base case to the control scenario. We found that estimated avoided mortalities were not significantly different between the 2,4 and $12 \mathrm{~km}$ resolution runs, but the $36 \mathrm{~km}$ resolution may over-predict some potential health impacts. Given the cost/benefit analysis requirements motivated by Executive Order 12866 as it applies to the Clean Air Act, the uncertainty associated with human health impacts and therefore the results reported in this study, we conclude that health impacts calculated from population weighted ozone concentrations obtained using regional photochemical models at $36 \mathrm{~km}$ resolution fall within the range of values obtained using fine (12 km or finer) resolution modeling. However, in some cases, $36 \mathrm{~km}$ resolution may not be fine enough to statistically replicate the results achieved using 2,4 or $12 \mathrm{~km}$
\end{abstract}

resolution. On average, when modeling at $36 \mathrm{~km}$ resolution, an estimated 5 deaths per week during the May through September ozone season are avoided because of ozone reductions resulting from the proposed emissions reductions (95\% confidence interval was 2-8). When modeling at 2, 4 or $12 \mathrm{~km}$ finer scale resolution, on average 4 deaths are avoided due to the same reductions ( $95 \%$ confidence interval was 1-7). Study results show that ozone modeling at a resolution finer than $12 \mathrm{~km}$ is unlikely to reduce uncertainty in benefits analysis for this specific region. We suggest that $12 \mathrm{~km}$ resolution may be appropriate for uncertainty analyses of health impacts due to ozone control scenarios, in areas with similar chemistry, meteorology and population density, but that resolution requirements should be assessed on a case-by-case basis and revised as confidence intervals for concentration-response functions are updated.

\section{Introduction}

Ground level ozone air pollution has been linked to adverse human health impacts and is regulated by numerous government authorities with the goal of protecting health. Predicting ozone concentrations and health impacts is subject to a number of sources of uncertainty (including emissions, chemistry, and health impacts), and thus uncertainty analyses for future regulations, including the potential impacts of climate change on ozone production, would be advantageous in a policy context. However, the ability to model ozone production is sensitive to model resolution, and it has been suggested that fine-scale modeling (at resolutions up to $2 \mathrm{~km}$ by $2 \mathrm{~km}$ ) is often necessary to reproduce ozone chemistry

Published by Copernicus Publications on behalf of the European Geosciences Union. 
if results are to be used to inform policy decisions (US EPA, 2007). Such computationally-intensive modeling at fine scale may limit uncertainty analyses or be infeasible for assessing future climate influence. Here, we compare the variation associated with simulated ozone at various model resolutions with uncertainty in estimated human health impacts, using population-weighted concentrations. We use the results of this analysis to evaluate the potential for using coarser-scale model resolution for uncertainty analyses of policies that impact future ozone.

Extensive analyses in the atmospheric chemistry literature have evaluated the impact of model resolution on ozone production (Arunachalam et al., 2006, 2011; Cohan et al., 2006; Jang et al., 1995; Tie et al., 2010; Valari and Menut, 2008) as well as ozone precursor concentration (Valin et al., 2011). Eulerian photochemical air quality models instantly and homogeneously disperse low level emissions (including ozone precursors Nitrogen Oxides and Volatile Organic Compounds, $\mathrm{NO}_{\mathrm{x}}$ and VOCs) throughout the grid cell. Spatial averaging impacts the chemistry by smoothing concentration gradients of precursors over large areas; in some cases, this smoothing has been shown to reduce modeled ozone titration effects and ozone formation hotspots. As a result, many studies have found that larger scale resolution (>12 km grid cells) leads to an under-prediction of daily maximum 8-h ozone averages, and an over-prediction of daily minimum 8-h ozone averages (Arunachalam et al., 2006; Jang et al., 1995; Tie et al., 2010). Some studies indicate that $12 \mathrm{~km}$ resolution is often not fine enough to capture sharp ozone concentration gradients that can occur near large sources of precursors, like power plants or dense urban areas with a lot of traffic (Kumar and Russel, 1996; Valeri and Menut, 2008). Similarly, Valin et al. (2011) found that $12 \mathrm{~km}$ resolution or finer is often needed in order to accurately represent $\mathrm{NO}_{2}$ chemistry near large $\mathrm{NO}_{\mathrm{x}}$ emissions sources. At a minimum, the US Environmental Protection Agency (EPA) requires a model grid resolution of $12 \mathrm{~km}$ by $12 \mathrm{~km}$ or smaller for regulatory-focused analyses using approved air quality models (with a coarse resolution modeling domain extending over all potentially contributing sources), but recommends that each case be evaluated independently to identify the potential model prediction improvements associated with finer scale resolution.

While previous studies have assessed the errors in predicted ozone versus measured concentrations, the influence of resolution-based errors on human health impacts remains uncertain. Arunchalam et al. (2011) assessed the health impacts associated with particulate matter from aircraft take off and landing at two airports in the US using $12 \mathrm{~km}$ and $36 \mathrm{~km}$ model resolution. They found that the estimated human health impacts varied by only $2 \%$ between the two model resolutions. The US EPA (2011a) conducted an uncertainty analysis as part of an evaluation of the US Clean Air Act (CAA). The goal of the study was to estimate the human health impacts of ozone and particulate matter concentrations in 2020 under the environmental regulation mandated by the CAA, versus likely concentrations of those two pollutants if the CAA were not implemented. While the uncertainty analysis addressed relative potential impacts of many uncertainties, probability distributions were included only for concentration response functions. With respect to uncertainties related to air quality modeling results, the US EPA argued that uncertainties in ozone benefits using a $12 \mathrm{~km}$ grid are likely minor, but primarily because the health benefits due to reductions in ozone are far outweighed by health benefits due to reductions in particulate matter (PM); they did not quantitatively compare results obtained by varying model resolution. Wesson et al. (2010) used calculated human health impacts to compare the performance of multi-pollutant versus single pollutant control strategies, and argued that assessing human health impacts is a better way to evaluate prospective policies than evaluating changes in ambient concentrations at monitored locations. The US National Research Council (NRC) has called for probabilistic multi-source uncertainty analyses in evaluating environmental policy (NRC, 2002).

A growing literature has used global models to approximate regional modeling to assess the potential impacts of climate change and future emissions on ozone concentrations. Several studies have used resolution of $36 \mathrm{~km}$ or coarser from climate models, often due to the coarse resolution at which most global scale models are run (Chang et al., 2010; Selin et al., 2009; West et al., 2007). Another common procedure is to use downscaling to model the regional air quality impacts of global change (Bell et al., 2007; Chen et al., 2009; Knowlton et al., 2004; Lam et al., 2011; Tagaris et al., 2009). Downscaling takes the output from global scale models and converts it to input for regional models. These input files can be gridded meteorological files covering the entire domain (instructing the regional model on meteorological conditions such as wind direction/speed and temperature), and/or initial and boundary conditions (instructing the regional model on initial concentrations of pollutions and concentrations of pollution that might move into the modeling domain from outside the boundary). While downscaling is most often applied to run regional models at $36 \mathrm{~km}, 12 \mathrm{~km}$ resolution modeling (Lam et al., 2011) is also possible. Results from downscaling can be applied to evaluate human health impacts as well. Bell et al. (2007) calculated a $0.11 \%$ to $0.27 \%$ increase (the $95 \%$ confidence interval) in mortality across 31 cities in the US based on the difference between modeled maximum daily ozone concentrations in five summers each around 2050 and the 1990s. Similarly, Knowlton et al. (2004) projected a $4.5 \%$ increase on average in mortality from acute exposure to ozone in New York state in 2050 due to climate change. Tagaris et al. (2009) evaluated the uncertainty associated with meteorological conditions based on the range of temperature and humidity values modeled by several global change models, concluding that uncertainty due to future meteorology was larger than uncertainty associated with human health impacts. Because of the increasing use of human health impact 
analyses from both global scale modeling and downscaling, it is important to evaluate how model resolution impacts the uncertainty associated with human health impacts of air pollution and to move towards identifying a resolution target for human health impact analyses.

Here, we evaluate the impact on modeled potential ozone exposure and calculated human health response uncertainty resulting from the temporal and spatial smoothing seen in coarse grid domains (Arunachalam et al., 2006; Jang et al., 1995; Tie et al., 2010) due to the spatial smoothing of ozone precursors, which can eliminate $\mathrm{NO}_{\mathrm{x}}$ titration and hot spot formation. Section 2 introduces the air quality modeling episode and the methods and equations used to evaluate model performance by spatial resolution, and calculate population weighted ozone metrics. Section 3.1 presents the results of the performance evaluation, which indicates that model output from each of the resolutions are more similar to each other than they are to measured values. Sections 3.2 and 3.3, respectively, present the population weighted ozone concentrations for each resolution and the changes in those values due to the proposed emissions controls. In Sect. 4, we focus on comparing the relative uncertainty associated with model resolution and resulting predicted ambient concentrations, with uncertainty associated with projected human health impacts by applying the changes in population weighted ozone concentrations calculated in Sect. 3.3 to concentration response functions obtained from the literature. In Sect. 5 we discuss possible sources of error. In Sect. 6, we use our results to identify a resolution appropriate for impacts analysis uncertainty for this case, taking into account relative errors and computational limitations. We finish in Sect. 6 with conclusions based on our analysis.

\section{Methods}

\subsection{Comprehensive Air Quality Model with Extensions (CAMx)}

We use CAMx version 4.5.3 (www.camx.com), a US EPAapproved regional air quality model (US EPA, 2007). We use a well-documented air quality episode developed in part during the Texas Air Quality Study II (TexAQSII) and selected as representative of high ozone episodes in this region (TCEQ, 2006, 2010a). The episode was created by the Texas Commission on Environmental Quality (TCEQ) for the Houston/Galveston/Brazoria (HGB) non-attainment area and includes a 2006 base case and a 2018 control policy scenario. Emissions inventories were speciated, and spatially and temporally processed using the Emissions Preprocessing System (EPS3). The 2006 base case inventory represents actual 2006 emissions, while the 2018 emissions inventories include proposed controls on ozone precursors (TCEQ, 2010b). On average, low level $\mathrm{NO}_{\mathrm{x}}$ emissions decrease by $44 \%$ from base case to control case, and low level CO emissions decrease by $30 \%$. The change in low level VOC from the 2006 base year to the 2018 control case is less than $\pm 5 \%$. The change in total emissions (low level plus elevated) is as follows for $\mathrm{NO}_{\mathrm{x}}, \mathrm{CO}$, and VOCs respectively: $-35 \%,-23 \%,+10 \%$. Please see the Supplementary Information for more detail on the changes in emissions. Elevated emissions are treated using the Plume In Grid capabilities in CAMx where the emissions plume is tracked and remains intact in the model until it reaches the size of a grid cell after which it is dumped to that grid cell.

Resolution of the original episode includes a coarse parent grid at $36 \mathrm{~km}$, and three nested grids at $12 \mathrm{~km}, 4 \mathrm{~km}$, and $2 \mathrm{~km}$ (Fig. 1). Meteorological inputs are the same in both scenarios and were developed using the fifth generation Penn State/NCAR mesoscale model MM5 (Grell et al., 1994) to represent conditions as they occurred on 13 August15 September 2006. MM5 was used to create meteorological input files for the 36, 12 and $4 \mathrm{~km}$ modeling domain; for the $2 \mathrm{~km}$ domain, meteorological data is interpolated by CAMx from $4 \mathrm{~km}$. A detailed description of the episode is provided by the TCEQ and includes a performance evaluation of the meteorological data (2010a). Meteorological inputs provide an additional source of uncertainty that is beyond the scope of this study (Vautard et al., 2012). Emissions totals are consistent across all resolutions, with $>2 \%$ variation in spatial distribution between resolutions. Performance of the episode was evaluated previously by the TCEQ (TCEQ. 2010a), and according to that evaluation met US EPA weight-of-evidence performance criteria (US EPA, 2007).

\subsection{Multiple Grid Performance analysis}

We focus here on what we will call the HGB area, or the area covered by the $2 \mathrm{~km}$ modeling domain (Fig. 1, red box). We conduct four simulations each for the two cases (2006 base case and 2018 control case), with increasingly coarse resolution over the HGB area $(2 \mathrm{~km}, 4 \mathrm{~km}, 12 \mathrm{~km}$, and $36 \mathrm{~km})$. We evaluate the performance of the 2006 base case in reproducing daily maximum 8 -h averaged ozone concentrations at air quality monitors in the region. This metric is selected for evaluation because it is necessary for input into concentration-response functions for impact analysis. We use the statistical measures Mean Normalized Bias (MNB) and Mean Normalized Gross Error (MNGE) as shown in Eqs. (1) and (2), respectively.

$$
\begin{aligned}
\text { MNB } & =\frac{1}{N} \sum_{1}^{N}\left(\frac{(\text { Model }- \text { Obs })}{\text { Obs }}\right) \times 100 \% \\
\text { MNGE } & =\frac{1}{N} \sum_{1}^{N}\left(\frac{\mid \text { Model }- \text { Obs } \mid}{\text { Obs }}\right) \times 100 \%
\end{aligned}
$$

\subsection{Health impacts}

For our analysis of health impacts and potential benefits, we use maximum daily population weighted 8 -h concentrations 


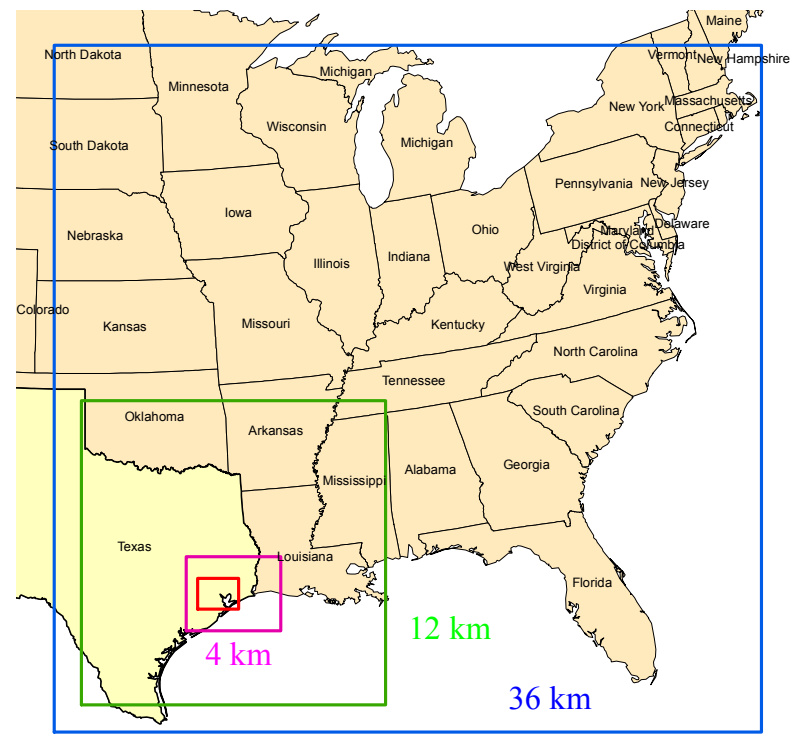

(a)

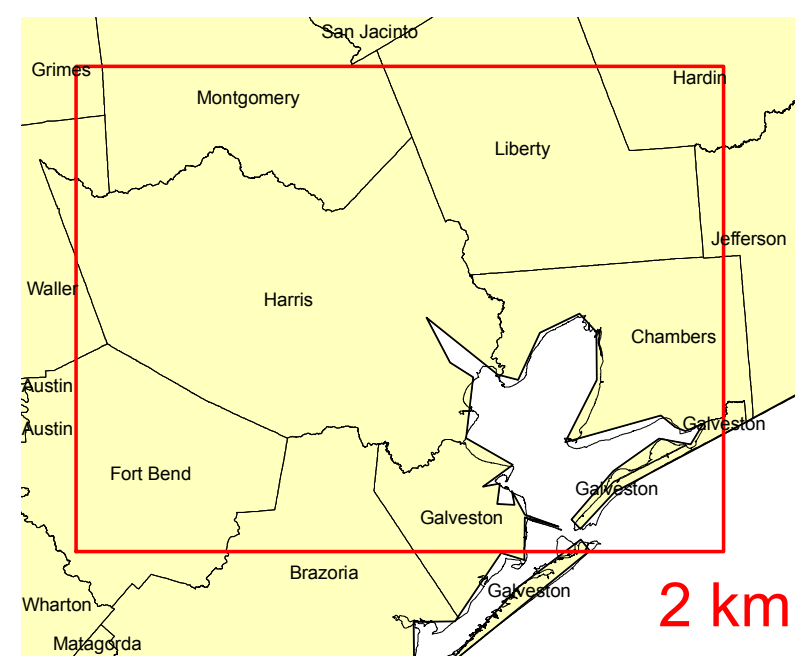

(b)

Fig. 1. CAMx Modeling domain. For each resolution, only the modeling results within the area covered by the $2 \mathrm{~km}$ domain (the HGB area), shown above in the red box, are used.

$\left(M_{\mathrm{pop}}\right)$ as a surrogate for exposure for both model and measurement calculated using Eq. (3).

$M_{\text {pop }}=\frac{\sum_{g}\left(p_{g} \times\left\{c_{g}\right\}\right)}{\sum_{g} p_{g}}$

where $p_{g}$ is the population in grid cell $g$, and $c_{g}$ is the daily maximum 8-h ozone concentration in grid cell $g$. Population distribution is from US Census data, provided with census block spatial detail, and is projected by GeoLytics (GeoLytics, 2010) and mapped to our modeling domain grid cells using Geographical Information System (GIS) software. For the base case, year 2007 is used, and for the 2018 policy case, projected 2015 population is applied. For populationweighted analysis of monitor data, only those grid cells with monitors located in them are used in the calculation, otherwise, all grid cells within the HGB area are included in the calculation. This metric represents a rough but best available and commonly-used estimate for the potential for human exposure. In reality, exposure depends not only on the ambient concentration of pollutants at any given time and location, but also on the daily patterns of people being exposed: when, where and how they travel to and from activities and their initial health (US EPA, 2010). The potential impacts on human health from changes in ozone concentrations are calculated by multiplying population-weighted concentrations by concentration response functions (and related $95 \%$ confidence intervals) for mortality from acute exposure. In order to evaluate sensitivity of our results to the selection of response function, we used three response functions generated by Anderson et al. (2004), Bell et al. (2004) and
Zanobetti and Schwartz (2008). The response functions selected for this study are those with published responses for daily maximum 8-h averaged ozone concentrations consistent with the latest EPA's Environmental Benefits Mapping and Analysis Program (BenMAP) (Abt, 2010) and the European ExternE study (Bickel and Friedrich, 2005). All response functions used here are nationally averaged, assume a linear relationship between daily maximum 8-h ozone concentrations and impacts, and assume no minimum health impact threshold (US EPA, 2011b). For baseline mortality rate, we used 2006 May through September (summer ozone season) average mortality for the city of Houston, as reported to the US Center for Disease Control (CDC, 2006). The use of nationally averaged concentration response functions could introduce an additional source of uncertainty that is not quantified in this paper. However, that uncertainty is tempered by the use of spatially and temporally averaged populationweighted ozone concentrations, and city-specific mortality data. Health response function data is often only available by county or city, meaning that for the purposes of health impact evaluation, these response functions are typically applied to large spatial domains covering multiple grid cells. Therefore we feel our methods are appropriately representative of common procedures. 


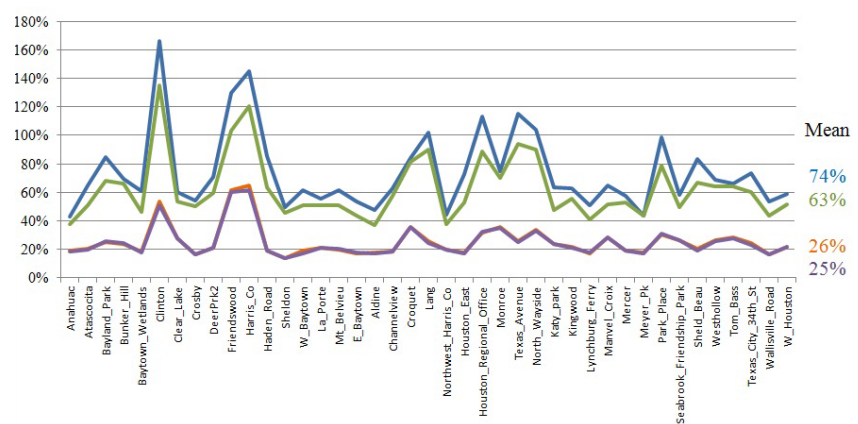

Individual Houston/Galveston/Brazoria Area Monitors $-36 \mathrm{kmMNGE}-12 \mathrm{kmMNGE}-4 \mathrm{kmMNGE} \quad-2 \mathrm{kmMNGE}$

(a)

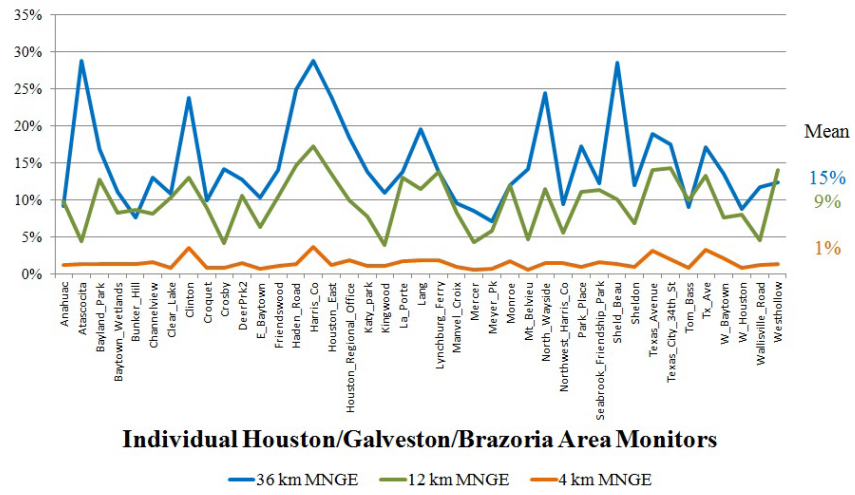

(b)

Fig. 2. (a): Mean Normalized Gross Error (MNGE) comparing CAMx results for four grid resolution runs for the 2006 base case to measured concentrations at all air quality monitor sites in the HGB area. Bias (MNB) and error (MNGE) results are approximately the same due to a high bias of the model, so only MNGE is shown in (a). Results are shown for $36 \mathrm{~km}$ (blue line), $12 \mathrm{~km}$ (green line), $4 \mathrm{~km}$ (orange line) and $2 \mathrm{~km}$ (purple line). $4 \mathrm{~km}$ results are very similar to $2 \mathrm{~km}$ results and as a result are mostly hidden by the $2 \mathrm{~km}$ line. (b): Difference between modeled "coarse" resolution ozone concentrations (36, 12 and $4 \mathrm{~km}$ ) and modeled $2 \mathrm{~km}$ "fine" resolution ozone concentrations calculated using Eq. (2) - MNGE.

\section{Comparison of monitor-based and population-based performance evaluation}

\subsection{6 base case: monitor-based analysis}

We first evaluated the performance of the 2006 base case episode with respect to the daily maximum 8 -h ozone concentrations modeled for each of the air quality monitors located in the HGB area for each of the four spatial resolution runs (these values do not take population into account). Figure 2a shows the MNGE (Eq. 2) in comparing ozone concentrations measured at monitor sites to model-simulated ozone concentrations in the grid cell containing the monitor (at each resolution). MNB is not reported because the model showed a constant positive bias and therefore MNGE and MNB are approximately equal. MNGE increases from $25 \%$ to $74 \%$

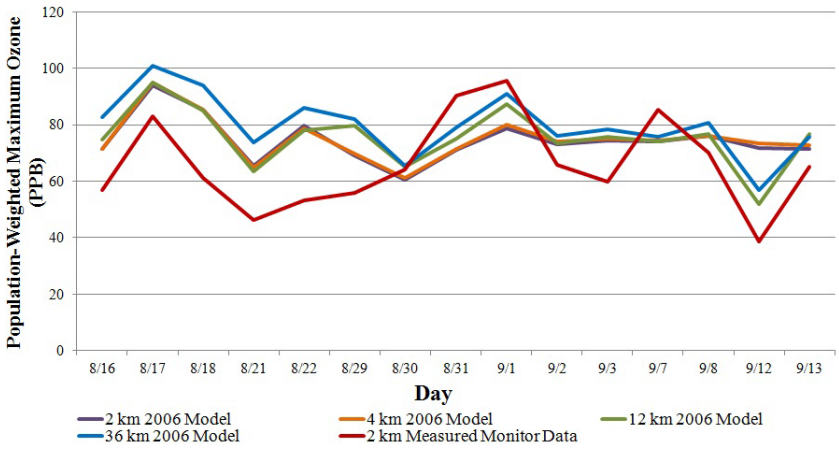

Fig. 3. Population-weighted maximum ozone concentration for each resolution from the 2006 episode compared to the populationweighted maximum ozone concentration calculated from the measured values at the monitors using the $2 \mathrm{~km}$ resolution. Modeled results are shown for $36 \mathrm{~km}$ (blue), $12 \mathrm{~km}$ (green), $4 \mathrm{~km}$ (orange) and $2 \mathrm{~km}$ (purple) and measured results are shown for $2 \mathrm{~km}$ (red).

as model resolution increases from $2 \mathrm{~km}$ to $36 \mathrm{~km}$. While an MNGE value of $74 \%$ does fall outside the commonly targeted range as reported by the US EPA (US EPA, 2007), we will show that estimated human health impacts are much less sensitive to model resolution choice than is pollutant concentration. Figure $2 \mathrm{~b}$ compares the difference between the three coarser resolutions relative to the $2 \mathrm{~km}$ fine scale modeling result (also calculated using Eq. 2 - MNGE); the difference in predicted ozone between coarser and finer scale resolution ranges from $1 \%-15 \%$. We conclude from this comparison that results from the different resolutions are more similar to each other than they are to actual measured values.

\subsection{6 base case: population-weighted analysis}

To assess a metric more relevant to health impacts, we compared the ability of the model run at different resolutions to reproduce population-weighted concentrations. Figure 3 shows the impact of resolution on the population-weighted concentrations as modeled using the 2006 base case. These results are compared to the measured concentrations at the monitors within the HGB area by multiplying the population within each monitor-containing $2 \mathrm{~km}$ by $2 \mathrm{~km}$ grid cell by the 8-h maximum ozone concentration measured at the corresponding monitor. In each case, for the values shown in Fig. 3, only the grid cells containing monitors and falling within the HGB area (as defined in Fig. 1) were used to calculate the population weighted ozone concentration. (For the human health impact analysis reported later in this paper, all grid cells within the HGB area were used to calculate population-weighted ozone concentrations.) Finer-resolution modeling (4 or $2 \mathrm{~km}$ ) exhibits no clear benefit in comparison with $12 \mathrm{~km}$ resolution when considering populationweighted concentrations. The $36 \mathrm{~km}$ simulation is biased 


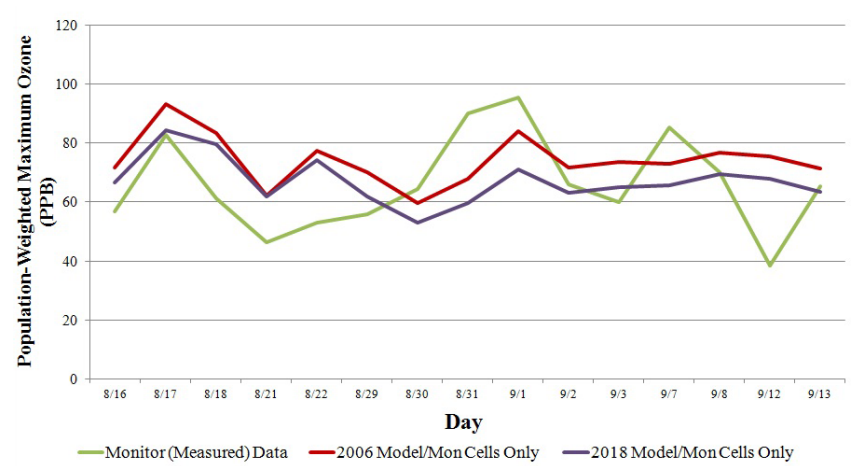

Fig. 4. Population weighted daily maximum 8 -h averaged ozone concentrations calculated using fine scale $2 \mathrm{~km}$ population, and ozone concentration data measured at monitors (green), or modeled ozone values from only the grid cells containing monitors from both the 2006 (red) and 2018 (purple) runs.

high (by 3 ppb resolution relative to finer scale model results); however, on average across all monitor locations, modeled concentrations are $10 \mathrm{ppb}$ higher than measured concentrations. On average, the difference between population weighted ozone concentration calculated using modeled concentrations in all grid cells within the HGB area versus only grid cells containing monitors was less than $1 \%$ for the 2006 base case and less than $2 \%$ for the 2018 control case for each of the four resolutions.

The 2006 base case episode overestimates the population weighted ozone concentrations derived from measured values on most days (as shown in Fig. 3). This bias is consistent with the monitor-based results presented in Sect. 3.1 above. Additionally, the model is not able to consistently capture the daily variability of the measured results. However, the results are improved over the standard performance evaluation statistics for $12 \mathrm{~km}$ and $36 \mathrm{~km}$ resolution as presented in Fig. 2. The MNGE of the population weighted daily maximum 8-h ozone concentrations modeled using the 2006 base case (and only cells containing monitors) compared to population weighted measured concentrations at air quality monitors average across the episode is $26 \%, 27 \%, 24 \%$ and $32 \%$ for $2 \mathrm{~km}, 4 \mathrm{~km}, 12 \mathrm{~km}$, and $36 \mathrm{~km}$ resolution respectively. The performance of the modeling episode at $2 \mathrm{~km}$ resolution, however, was judged adequate for regulatory purposes in the US based on modeled ozone concentrations.

\subsection{6 base case vs. 2018 control case: population-weighted comparison}

We compared population-weighted ozone changes between the 2006 base case with the 2018 control case, to identify the variation in concentration between different resolutions for benefits analysis. Figure 4 shows a comparison of population weighted ozone concentrations (Eq. 3), calculated using only the HGB area grid cells containing monitors, for the

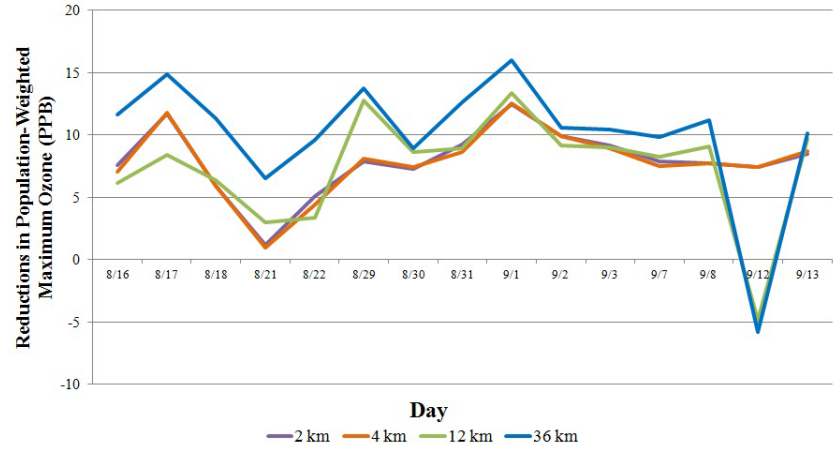

Fig. 5. Impact of 2018 control scenario (2018 Control case - 2006 Base case) on daily maximum 8-h ozone population weighted ozone concentration by resolution using all grid cells within the HGB area. Results are shown for $36 \mathrm{~km}$ (blue), $12 \mathrm{~km}$ (green), $4 \mathrm{~km}$ (orange) and $2 \mathrm{~km}$ (purple).

measured 2006 values, the 2006 base case modeled values modeled at $2 \mathrm{~km}$ resolution, and the 2018 control case values, modeled at $2 \mathrm{~km}$ resolution.

Figure 5 shows the change in population weighted 8-h ozone concentrations from base case 2006 model data to control case 2018 model data for all grid cells and population within the HGB area. Based on these results, the control scenarios in the 2018 episode clearly impact the modeled ozone concentrations in the HGB area, with an average $10 \mathrm{ppb}$ decrease in both population weighted concentrations and maximum daily 8-h ozone concentration from 2006 base case results. The calculated population weighted ozone decrease differs depending on what model resolution is used: the average decrease is $8 \mathrm{ppb}$ for both the $2 \mathrm{~km}$ and $4 \mathrm{~km}$ model resolutions, $7 \mathrm{ppb}$ for the $12 \mathrm{~km}$ model resolution, and $10 \mathrm{ppb}$ for the $36 \mathrm{~km}$ resolution. For comparison, the average change in the fourth highest daily maximum 8-h ozone at all monitors located within the HGB area is $8 \mathrm{ppb}, 7 \mathrm{ppb}, 7 \mathrm{ppb}$ and $6 \mathrm{ppb}$, respectively.

The benefits to air quality that are seen in the 2018 control scenario are due to the $35 \%$ and $23 \%$ average decrease in $\mathrm{NO}_{\mathrm{x}}$ and $\mathrm{CO}$ emissions, respectively, from the 2006 base case to the 2018 control case, within the HGB area. VOC emissions increase by $10 \%$ from 2006 to 2018 .

\section{Uncertainty analysis of health impacts at varying model resolution}

We use the change in population weighted daily maximum 8-h ozone in the HGB area, shown above in Fig. 5, averaged across all days of the episode, to calculate the expected health benefits from the policy case (the control scenario). We use these values to compare the estimated benefits that would be calculated based on concentrations predicted using modeling results at each of the four resolutions, and 
concentration-response functions with $95 \%$ confidence intervals as described above.

Table 1 shows the calculated change in mortalities per week during the May through September ozone season, between 2006-2018, based on modeled population-weighted concentration data within the HGB area, from the four different modeling resolutions. Also shown is the total number of mortalities per week in 2006 calculated using concentrations measured at air quality monitors in the HGB area. For each endpoint, the mean value is based on the concentration response functions, and is followed by the $95 \%$ confidence interval, the uncertainty is associated with concentration response functions only. The mean (5) and $95 \%$ confidence interval (2-7) for the change in mortalities per week calculated using data from Anderson et al. (2004) is identical up to $12 \mathrm{~km}$. For $36 \mathrm{~km}$ resolution, the mean is 6 and $95 \%$ confidence interval 2-9 for decrease in mortalities based on the 2018 control case. Base year (2006) mortality based on monitored data is calculated to be between 14 and 60 deaths per week during the May through September ozone season due to acute exposure, with a mean of 42 . The avoided mortalities due to acute exposure calculated using national functions developed by Bell et al. (2004) and Zanobetti and Schwartz (2008) both show slightly lower mean values to the mortalities calculated using functions from Anderson et al. (2004). Results obtained using functions from Bell et al. show a smaller uncertainty range while Zanobetti and Schwartz functions show a larger uncertainty range. These three results are presented to help show that the general result is insensitive to the function used. The spread of the confidence interval will determine how accurate the air quality data needs to be. As confidence in human health functions improves, there will be less overlap between results calculated from each resolution and therefore differences between resolutions may become significant. However, more recently published functions (Zanobetti and Schwartz, 2008) show wider uncertainty ranges than the two older functions presented.

We also evaluated two additional morbidity health impacts (minor restricted activity days and bronchodilator usage) and drew the same conclusions as from the mortality results (specifically that $36 \mathrm{~km}$ resolution could over-estimate the benefits from control scenarios versus finer scale modeling). Morbidity estimation was based on nation-wide health incident baseline occurrences.

The US EPA has found, however, that most of the monetary benefits associated with health improvements come from reduction in mortalities due to the high value of a statistical life (US EPA, 2011a).

It is important to note that in all health impacts shown in Table 1, the mean value predicted by the model at $36 \mathrm{~km}$ resolution falls within the $2 \mathrm{~km}$ uncertainty range, indicating that by using the mean coarse resolution results, one would not make an error in prediction according to the finer resolution results. This result is supported by the similar results
Table 1. Change in mortality for each week of the May through September ozone season for the population located within the HGB area, due to the control scenarios proposed as part of the 2018 Houston Attainment Demonstration versus the 2006 base case. The top row shows baseline weekly mortality due to ozone measured at monitors in 2006 . Each entry shows mean value with the $95 \%$ confidence interval (based on uncertainty associated with concentration response functions only) given in parentheses.

\begin{tabular}{|c|c|c|c|}
\hline \multicolumn{4}{|c|}{$\begin{array}{l}\text { Mortality in HGB Area Mean with } 95 \% \text { Confidence Interval } \\
\text { (Deaths per Week during May through September) }\end{array}$} \\
\hline & Anderson & Bell & Zanobetti \\
\hline \multicolumn{4}{|c|}{$\begin{array}{l}\text { Total Basecase Mortality Calculated Using Population Weightec } \\
\text { Concentrations as Measured by Air Quality Monitors in } 2006 \\
\text { (Monitor-containing cells only) }\end{array}$} \\
\hline 06 Monitor Data & $42(14,60)$ & $30(19,41)$ & $35(4,68)$ \\
\hline \multicolumn{4}{|c|}{$\begin{array}{c}\text { Change (Decrease) in Mortality between the } 2006 \text { Modeled } \\
\text { Basecase and the } 2018 \text { Modeled Control Case } \\
\text { (All cells within the } 2 \mathrm{~km} \text { domain) }\end{array}$} \\
\hline Model $2 \mathrm{~km}$ & $5(2,7)$ & $4(2,5)$ & $4(0,8)$ \\
\hline Model 4 km & $5(2,7)$ & $4(2,5)$ & $4(0,8)$ \\
\hline Model $12 \mathrm{~km}$ & $5(2,7)$ & $3(2,5)$ & $4(0,8)$ \\
\hline Model $36 \mathrm{~km}$ & $6(2,9)$ & $5(3,6)$ & $5(1,10)$ \\
\hline
\end{tabular}

obtained by Arunchalam et al. (2011) who evaluated the impact of model resolution on human health impacts from secondary fine particulate matter associated with emissions from aircraft take-off and landing. They found that calculated human health impacts were not sensitive to model resolution up to $36 \mathrm{~km}$.

\section{Process analysis}

We use the CAMx Process Analysis (PA) tool to calculate individual contributions from each physical and chemical process within the model, to the final concentration of ozone. This allows us to better understand the cause of the resolution-dependent differences in our study. We used PA and the python based Process Analysis (pyPA) postprocessing tool developed by Henderson et al. (2011) to analyze results for 12 September because that day had the largest difference between the 2006 base case and the 2018 control case (Fig. 5). For each resolution, the area included in the Process Analysis was the HGB area in the horizontal, and up to the mixing height (determined for each hour of the day by the pyPA program) in the vertical. Our results indicate that the resolution difference is due to chemistry: ozone destruction due to excess $\mathrm{NO}_{\mathrm{x}}$ in the $12 \mathrm{~km}$ and $36 \mathrm{~km}$ resolution models reduces the contribution to ozone from chemistry during the hours of $10 \mathrm{a} . \mathrm{m}$. to 12 Noon $(12 \mathrm{ppb}$ per hour in the fine resolution models vs. $6 \mathrm{ppb}$ per hour in the coarse resolution models).

To aid the process analysis evaluation, the $\mathrm{NO}_{\mathrm{x}}$ emissions totals were summed up for each of the three "fine" model 
resolution domains and compared to the $\mathrm{NO}_{\mathrm{x}}$ totals in each corresponding grid cell within the $36 \mathrm{~km}$ resolution. The fine resolution domains were also compared to each other. The same procedure was used to compare the total $\mathrm{CO}$, and VOC emissions between the resolutions. In all cases, the spatial distribution of $\mathrm{NO}_{\mathrm{x}}, \mathrm{CO}$ and VOC emissions were within $2 \%$ between the resolutions. This result and the process analysis findings both indicate that the large differences in ozone concentrations that occur on 12 September are a function of the model resolution and the resulting differences in spatial distribution of emissions, not the emissions totals.

\section{Conclusions and implications for benefits analysis}

To evaluate the uncertainty associated with air quality modeling resolution for calculating health benefits of proposed policies, we ran one modeling episode with two emissions inventories (a base case and a control scenario, both for Houston, Texas) at $36,12,4$ and $2 \mathrm{~km}$ resolution. We evaluated base case model performance for each resolution for monitor-based calculations of 8-h maximum ozone. Results from each resolution were more similar to each other than they are to actual measured values. Additionally, we evaluated the model predicted values of population-weighted calculations of 8-h maximum ozone using the same statistics we used to evaluate the daily 8 -h maximum. We found the model was better able to reproduce these derived values than the 8$\mathrm{h}$ maximum concentrations (the latter being the focus of the regulatory process).

We compared the difference in the population weighted ozone concentrations, calculated using the overlapping area of the four resolutions between resolutions and between the 2006 base case and the 2018 control case. The coarse scale resolution $(36 \mathrm{~km})$ showed the largest decrease from base case to control scenario case. The average change in daily maximum 8-h ozone population weighted concentrations are $10 \mathrm{ppb}, 7 \mathrm{ppb}, 8 \mathrm{ppb}$ and $8 \mathrm{ppb}$ for $36 \mathrm{~km}, 12 \mathrm{~km}, 4 \mathrm{~km}$, and $2 \mathrm{~km}$ resolution respectively.

We used the population-weighted ozone concentration difference to calculate change in mortality from acute exposure due to the proposed control scenario. The mean value for change in mortality, calculated using coarse resolution model results, fell within the health impact response range of uncertainty as calculated by the $2 \mathrm{~km}$ resolution for all three mortality response functions evaluated. However, the $36 \mathrm{~km}$ results have the potential to overestimate the benefits to human health when compared to the results obtained using fine scale modeling.

Given the uncertainty associated with human health impacts and therefore the results reported in Table 1, we conclude that population weighted ozone concentrations obtained using regional photochemical models at $36 \mathrm{~km}$ resolution have the potential to overestimate the benefits associated with human health impacts relative to values obtained using fine (12 km or finer) resolution modeling. However, because the median values of all health impacts evaluated that were calculated using coarse modeling do fall within the health impact uncertainty range of fine resolution results, there does exist the possibility for uncertainty analyses (for example: Monte Carlo analysis) on $36 \mathrm{~km}$ resolution air quality modeling results, which are on average 300 times more computationally efficient than running the same episode and same domain with $2 \mathrm{~km}$ resolution. Further applications of this methodology to different regions are necessary to address whether similar resolution requirements apply to ozone production regimes different from the Houston area with its complicated mix of petrochemical industry and transportation emissions, and coastal meteorological challenges (Parrish et al., 2011). However, as human health response becomes better known and the span of the uncertainty range decreases, more accurate air quality modeling results will be needed, potentially requiring the use of finer scale modeling. This result is important given the increasing use of global scale models in research related to human health as many global scale models are run at resolutions coarser than even $36 \mathrm{~km}$.

\section{Supplementary material related to this article is available online at: http://www.atmos-chem-phys.net/12/ 9753/2012/acp-12-9753-2012-supplement.pdf.}

Acknowledgements. The research described has been supported by the US Environmental Protection Agency's STAR program through grant R834279 and by the MIT Joint Program on the Science and Policy of Global Change. It has not been subjected to any US EPA review and therefore does not necessarily reflect the views of the Agency, and no official endorsement should be inferred. The authors would also like to thank Barron Henderson, at the University of Florida, for assistance with the valuable pyPA process analysis tool.

Edited by: W. Lahoz

\section{References}

Abt Associates Inc: BenMAP, Environmental Benefits Mapping and Analysis Program, User's Manual, Prepared for the US EPA Office of Air Quality Planning and Standards, available at: http://www.epa.gov/airquality/benmap/docs.html (last access: July 2012), August 2010.

Anderson, H. R., Atkinson, R. W., Peacock, J. L., Marston, L., and Konstantinou, K.: Metaanalysis of timeseries studies and panel studies of particulate matter $(\mathrm{PM})$ and ozone $\left(\mathrm{O}_{3}\right)$, Report of a WHO task group, World Health Organization, available at: http://www.euro.who.int/document/e82792.pdf (last access: June 2011), 2004.

Arunachalam, S., Holland, A., Do, B., and Abraczinskas, M.: A quantitative assessment of the influence of grid resolution on predictions of future-year air quality in 
North Carolina, USA, Atmos. Environ., 40, 5010-5026, doi:10.1016/j.atmosenv.2006.01.024, 2006.

Arunachalam, S., Wang, B., Davis, N., Baek, B. H., and Levy, J. I.: Effect of chemistry-transport model scale and resolution on population exposure to $\mathrm{PM}_{2.5}$ from aircraft emissions during landing and takeoff, Atmos. Environ., 45, 3294-3300, doi:10.1016/j.atmosenv.2011.03.029, 2011.

Bell, M. L., McDermott, A., Zeger, S. L., Sarnet, J. M., and Dominici, F.: Ozone and short-term mortality in 95 us urban communities, 1987-2000, JAMA: J. Am. Med. Assoc., 292, 23722378, doi:10.1001/jama.292.19.2372, 2004.

Bell, M. L., Goldberg, R., Hogrefe, C., Kinney, P., Knowlton, K., Lynn, B., Rosenthal, J., Rosenzweig, C., and Patz, J.: Climate change, ambient ozone, and health in 50 US cities, Climatic Change, 82, 61-76, doi:10.1007/s10584-006-9166-7, 2007.

Bickel, P. and Friedrich, R. (Eds.): ExternE: Externalities of Energy, Methodology 2005 Update, 2005.

CDC: "Morbidity and Mortality Weekly Report", Center for Disease Control and Prevention, available at: http://wonder.cdc.gov/ mmwr/mmwr $\backslash$ reps.asp (last access: December 2011), 2006.

Chang, H. H., Zhou, J., and Fuentes, M.: Impact of Climate Change on Ambient Ozone Level and Mortality in Southeastern United States, Int. J. Environ. Res. Public Health, 7, 2866-2880, doi:10.3390/ijerph7072866, 2010.

Chen, J., Avise, J., Lamb, B., Salathé, E., Mass, C., Guenther, A., Wiedinmyer, C., Lamarque, J.-F., O’Neill, S., McKenzie, D., and Larkin, N.: The effects of global changes upon regional ozone pollution in the United States, Atmos. Chem. Phys., 9, 11251141, doi:10.5194/acp-9-1125-2009, 2009.

Cohan, D. S., Hu, Y., and Russell, A. G.: Dependence of ozone sensitivity analysis on grid resolution, Atmos. Environ., 40, 126135, doi:10.1016/j.atmosenv.2005.09.031, 2006

GeoLytics Inc.: Census 2015 Projection Methods, available at: http://geolytics.com/USCensus, Estimates-Projections, Data, Methodology,Products.asp (last access: November 2011), 2010.

Grell, G., Dudhia, J., and Stauffer, D. R.: A description of the fifth generation Penn State/NCAR mesoscale model (MM5), Tech. Note NCAR/TN-398+STR, National Center for Atmospheric Research, Boulder, CO, 1994.

Henderson, B. H., Kimura, Y., McDonald-Buller, E., Allen, D. T., and Vizuete, W.: Comparison of Lagrangian Process Analysis tools for Eulerian air quality models, Atmos. Environ., 45, 52005211, doi:10.1016/j.atmosenv.2011.06.005, 2011.

Jang, J.-C. C., Jeffries, H. E., and Tonnesen, S.: Sensitivity of ozone to model grid resolution - II. Detailed process analysis for ozone chemistry, Atmos. Environ., 29, 3101-3114, doi:10.1016/13522310(95)00119-J, 1995.

Knowlton, K., Rosenthal, J. E., Hogrefe, C., Lynn, B., Gaffin, S., Goldberg, R., Rosenzweig, C., Civerolo, K., Ku, J.-Y., and Kinney, P. L.: Assessing Ozone-Related Health Impacts under a Changing Climate, Environ. Health Perspect., 112, 1557-1563, doi:10.1289/ehp.7163, 2004.

Kumar, N. and Russell, A. G.: Multiscale air quality modeling of the Northeastern United States, Atmos. Environ., 30, 1099-1116, doi:10.1016/1352-2310(95)00317-7, 1996.

Lam, Y. F., Fu, J. S., Wu, S., and Mickley, L. J.: Impacts of future climate change and effects of biogenic emissions on surface ozone and particulate matter concentrations in the United States, Atmos. Chem. Phys., 11, 4789-4806, doi:10.5194/acp-11-4789-
2011, 2011.

NRC (National Research Council): Estimating the Public Health Benefits of Proposed Air Pollution Regulations, National Academies Press, Washington, DC, 2002.

Parrish, D. D., Singh, H. B., Molina, L., and Madronich, S.: Air quality progress in North American megacities: A review, Atmos. Environ., 45, 7015-7025, doi:10.1016/j.atmosenv.2011.09.039, 2011.

Selin, N. E., Wu, S., Nam, K. M., Reilly, J. M., Paltsev, S., Prinn, R. G., and Webster, M. D.: Global health and economic impacts of future ozone pollution, Environ. Res. Lett., 4, 044014, doi:10.1088/1748-9326/4/4/044014, 2009.

Tagaris, E., Liao, K.-J., DeLucia, A. J., Deck, L., Amar, P., and Russell, A. G.: Potential Impact of Climate Change on Air PollutionRelated Human Health Effects, Environ. Sci. Technol., 43, 49794988, doi:10.1021/es803650w, 2009.

TCEQ: TexAQSII Field Study, available at: http://www.tceq.texas. gov/airquality/research/texaqs (last access: January 2010), 2006.

TCEQ: Air Quality Modeling Files ftp Site, available at: ftp://ftp. tceq.state.tx.us/pub/OEPAA/TAD/Modeling/ (last access: January 2010), 2010a.

TCEQ: Houston-Galveston-Brazoria Attainment Demonstration and Reasonable Further Progress State Implementation Plan Revisions for the 1997 Eight-Hour Ozone Standard, 10 March 2010, available at: http://www.tceq.texas.gov/airquality/ sip/HGB $\backslash$ eight $\backslash$ hour.html, 2010b.

Tie, X., Brasseur, G., and Ying, Z.: Impact of model resolution on chemical ozone formation in Mexico City: application of the WRF-Chem model, Atmos. Chem. Phys., 10, 8983-8995, doi:10.5194/acp-10-8983-2010, 2010.

US EPA: Guidance on the Use of Models and Other Analyses for Demonstrating Attainment of Air Quality Goals for Ozone, $\mathrm{PM}_{2.5}$, and Regional Haze, Office of Air Quality Planning and Standards, Report B-07-002, available at: http://www.epa.gov/ scram001/guidance/guide/final-03-pm-rh-guidance.pdf, April 2007.

US EPA: Stochastic Human Exposure and Dose Simulation (SHEDS) Multimedia Model Version 3, Office of Research and Development: Human Exposure and Atmospheric Sciences, available at: http://www.epa.gov/heasd/products/sheds $\backslash$ multimedia/sheds $\backslash \mathrm{mm}$.html, 2010.

US EPA: The Benefits and Costs of the Clean Air Act from 1990 to 2020, Office of Air and Radiation, Second Prospective Study, available at: http://www.epa.gov/oar/sect812/prospective2.html (last access: May 2011), 2011a.

US EPA: Integrated Science Assessment for Ozone and Related Photochemical Oxidants, Office of Research and Development, available at: http://yosemite.epa.gov/sab/Ozone_ISA_ERD1.pdf (last access: May 2011), 2011b.

Valari, M. and Menut, L.: Does an Increase in Air Quality Models' Resolution Bring Surface Ozone Concentrations Closer to Reality?, J. Atmos. Oceanic. Tech., 25, 1955-1968, doi:10.1175/2008JTECHA1123.1, 2008.

Valin, L. C., Russell, A. R., Hudman, R. C., and Cohen, R. C.: Effects of model resolution on the interpretation of satellite $\mathrm{NO}_{2}$ observations, Atmos. Chem. Phys., 11, 11647-11655, doi:10.5194/acp-11-11647-2011, 2011.

Vautard, R., Moran, M. D., Solazzo, E., Gilliam, R. C., Matthias, V., Bianconi, R., Chemel, C., Ferreira, J., Geyer, B., Hansen, A. 
B., Jericevic, A., Prank, M., Segers, A., Silver, J. D., Werhahn, J., Wolke, R., Rao, S. T., and Galmarini, S.: Evaluation of the meteorological forcing used for the Air Quality Model Evaluation International Initiative (AQMEII) air quality simulations, Atmos. Environ., 53, 15-37, doi:10.1016/j.atmosenv.2011.10.065, 2012.

Wesson, K., Fann, N., Morris, M., Fox, T., and Hubbell, B.: A Multi-pollutant, risk-based approach to air quality management: Case study for Detroit, Atmos. Pollut. Res., 296-304, doi:10.5094/APR.2010.037, 2010.
West, J. J., Szopa, S. and Hauglustaine, D. A.: Human mortality effects of future concentrations of tropospheric ozone, C. R. Geosci., 339, 775-783, doi:10.1016/j.crte.2007.08.005, 2007.

Zanobetti, A. and Schwartz, J.: Is there adaptation in the ozone mortality relationship: A multi-city case-crossover analysis, Env. Health, 7, 22, doi:10.1186/1476-069X-7-22, 2008. 